Historia y comunicación social

ISSN: 1137-0734

http://dx.doi.org/10.5209/hics.75712

\title{
La geografía periodística madrileña en la Edad de Oro del periodismo español: la dialéctica entre vieja y nueva prensa y su reflejo en el espacio urbano
}

Juan Carlos Sánchez Illán

Recibido el: 9 de enero de 2020/ Aceptado: 14 de diciembre de 2020

Resumen. A través del análisis de la geografía periodística madrileña, se observan dos patrones de localización en el espacio urbano. El estudio de sus modelos y taxonomía de implantación es absolutamente novedoso. La relación dialéctica entre vieja y nueva prensa no solo tiene su reflejo en las páginas de los grandes medios periodísticos sino en el propio ámbito madrileño. La vieja prensa del siglo XIX se ubica en el Distrito Centro, en torno al eje transversal configurado por el Palacio Real, la Puerta del Sol y la Carrera de San Jerónimo. Las grandes empresas periodísticas que nacen en el siglo XX, la llamada nueva prensa, por su parte, prefiere marcar distancias, ubicándose en los nuevos horizontes del Ensanche, en el entorno de los Bulevares y el Barrio de Salamanca.

Palabras clave: Prensa; sedes; lugares de memoria; geografía urbana; Madrid.

[en] Madrid journalistic geography in the Golden Age of Spanish journalism: the dialectic between old and new media and its reflection in the urban space

\begin{abstract}
Through the analysis of Madrid journalistic geography, it can be seen two patterns of localization in the urban space. The study of their models and taxonomy of implementation is quite original. The dialectical relationship between Old and New press is not only reflected in the pages of the big media, but in the Madrid field. Old press from the 19th century is located in the Downtown district, around the transversal axis set by the Royal Palace, Puerta del Sol and the Carrera de San Jerónimo. The big media companies that are born in the 20th century, the so-called New press, on the other hand, prefer to mark distances, reaching the new horizons of the Ensanche, in the surroundings of the boulevards and the Barrio de Salamanca.
\end{abstract}

Keywords: Press; Headquarters; Places of memory; Urban geography; Madrid.

Sumario: 1. Introducción. Un modelo de implantación de la prensa en el espacio urbano madrileño. 2. El modelo de la vieja prensa del siglo xix. 3. El patrón urbano de referencia para la prensa del primer tercio del siglo XX. 3.1. Un cambio superficial... para que todo siga igual. 4. Conclusiones. Un impulso para la prensa madrileña desde la ciudad condal. La prensa se industrializa.

Cómo citar: Sánchez Illán, J. C. (2020) La geografía periodística madrileña en la Edad de Oro del periodismo español: la dialéctica entre vieja y nueva prensa y su reflejo en el espacio urbano, Historia y comunicación social 26(1), 249-262.

\section{Introducción. Un modelo de implantación de la prensa en el espacio urbano madrileño}

La ciudad de Madrid, al igual que París -su referente cultural e histórico, al menos desde la llegada al Trono de los Borbones en el siglo XVIII-, ha sido la capital indiscutible de la imprenta, del periodismo y de la política y, en consecuencia, un fiel exponente del sustancialmente politizado modelo de esfera pública española. Durante el periodo de la Restauración canovista, entre 1875 y 1923, se asiste, en particular, a la configuración de un peculiar modelo centralizado de prensa, liberal oligárquico, acorde con el sistema político de turno de partidos, en el que importan más los intereses elitistas de la opinión publicada que los de la opinión pública.

El caso español es, además, el de un prototipo de periodismo que, desde sus inicios, aparece indefectiblemente asociado a una relación sinérgica -en su naturaleza y praxis- de la esfera política construida en la capital del Estado. Esto es así, fundamentalmente, porque carece del suficiente músculo y envergadura empresarial -sobre todo por los consabidos motivos estructurales de falta de difusión y de público lector- como para poder configurar y constituir una esfera pública propia de los medios periodísticos, al menos relativamente

Universidad Carlos III de Madrid

E-mail: jcsanche@hum.uc3m.es

ORCID: https://orcid.org/0000-0002-5692-8022

Hist. comun. soc. 26(1) 2021: 249-262 
autónoma, de la esfera política. De hecho, su directísima interconexión con la vida política será uno de los rasgos definitorios y estructurales $-\mathrm{y}$, por tanto, permanentes- que definan su existencia y su devenir, hasta la llegada y consolidación de la democracia constitucional, en los años 80 del siglo XX.

Es preciso abordar esta interrelación desde la perspectiva de la Prensa -con mayúsculas, como institución y auténtico cuarto poder- que ocupa un lugar concreto en el espacio urbano. También desde una perspectiva dialéctica entre vieja y nueva prensa que no solo tiene su reflejo en las páginas de los grandes diarios de información general sino en el propio territorio madrileño. Se trata de un sujeto y objeto de estudio que se aborda por primera vez en la historiografía española: el análisis de la labor de emprendimiento de los propietarios y la localización geográfica de sus grandes edificios y sedes editoriales como epicentro de cuestiones estratégicas en la propia evolución y cambio histórico de los medios periodísticos. Una disección de la prensa, en suma, desde el punto de vista espacial, planteado desde la hipótesis de que la ubicación de las grandes empresas editoras obedece a unas pautas no solo empresariales sino incluso ideológicas y editoriales ${ }^{2}$.

Desde este punto de vista, los espacios físicos de las empresas periodísticas son, además, lugares de memoria, en sentido estricto, tanto desde el punto de vista material, simbólico como, sobre todo, funcional ${ }^{3}$. La sede de los grandes periódicos es un lugar privilegiado y crucial de interacción cultural, social y política. Al mismo tiempo que un espacio de creación de cultura política, de círculos y agrupaciones de élites que van a dar lugar a los partidos políticos ${ }^{4}$. En este sentido, este trabajo pretende también ser una reivindicación de unos espacios singulares y de la consiguiente necesidad de que cuenten con especial protección y, al menos, con placas informativas y memoriales.

La ciudad de Madrid durante la segunda mitad del siglo XIX puede ser considerada, desde un punto de vista de desarrollo urbanístico, como una entidad de crecimiento relativamente anárquico, con la excepción de los Ensanches del Barrio de Salamanca y de los Bulevares que intentan seguir, sobre todo, el modelo parisino. Los grandes negocios, eso sí, se encuentran preferentemente en el entorno de los Paseos del Prado y de Recoletos 5 . En Madrid no ha existido, sin embargo -y esto es muy importante subrayarlo-, un Barrio o Distrito de la Prensa específico, como el caso de Fleet Street en Londres o el Barrio de la Bolsa, el Quartier de la Presse en París -la denominada République du croissant, situada entre Réaumur y Opéra, en las cercanías del Mercado financiero y de los Grandes Bulevares-, aunque, como ya se ha dicho, París ha sido sin duda la referencia ineludible para la prensa de Madrid. En este sentido, hay que recordar que los epicentros de la prensa de referencia europea tenían habitualmente como eje la proximidad a la Bolsa, caso de París y de Londres, siendo pioneras, en su modelo de implantación, las grandes agencias de noticias nacionales, Havas y Reuters, respectivamente. En Madrid, por su parte, la Bolsa no tuvo una ubicación estable hasta una fecha tan tardía como 1893, cuando se inauguró en la Plaza de la Lealtad su actual sede, junto al Paseo del Prado, en el Barrio de los Jerónimos, Distrito de Retiro, lo cual habla asimismo de la relativa debilidad de su capitalismo financiero. Sin embargo, en relación a la prensa madrileña -entendida funcionalmente como institución y cuarto poder-, sí que puede afirmarse la existencia desde el siglo XIX de una directa correlación entre su ubicación en el espacio urbano madrileño, sus condicionantes estructurales y empresariales y sus posicionamientos ideológicos.

En la nueva sociedad urbana madrileña de la Restauración hay que tener en cuenta su más que notable papel como generadores de espacios de sociabilidad -de esfera pública habermasiana- y su lugar más que relevante en la vida política y social. No puede extrañar, pues, que unos medios periodísticos tan extremadamente politizados muestren su interacción en la geografía social y periodística madrileña, de acuerdo a ciertos esquemas y patrones predeterminados ${ }^{6}$.

Desde este punto de vista, en el ecosistema de la prensa madrileña se aprecian dos grandes modelos o patrones de implantación en el espacio urbano. El universo de la denominada como la vieja prensa del siglo XIX, marcada por su íntima vinculación a las élites políticas, muestra su preferencia por el Distrito Centro, en las cercanías de la Puerta del Sol -el tradicional mentidero y rompeolas de todas las Españas-y la aledaña Carrera de San Jerónimo, donde se encuentra la sede del Congreso de los Diputados y de la soberanía nacional. De hecho, el Palacio del Congreso es uno de los edificios más emblemáticos del Madrid liberal del siglo XIX. De estilo neoclásico, fue construido a partir de 1843 e inaugurado el 31 de octubre de 1850, coincidiendo

En el terreno de la creación literaria, hay precedentes. Franco Moretti en Atlas de la novela europea, 1800-1900, Madrid, Siglo XXI, 1999, aborda la tesis de que la geografía es una fuerza activa, concreta, que deja huellas profundas sobre la invención literaria por lo que, en su obra, se exploran las relaciones entre formas simbólicas y formas políticas.

En el sentido fuerte que le dio a este concepto Pierre Nora (dir.), en su monumental Les Lieux de mémoire (dir.), París, Gallimard (Bibliothèque illustrée des histoires), 3 tomos: t. 1 La République (1 vol., 1984), t. 2 La Nation (3 vol., 1987), t. 3 Les France (3 vol., 1992).

Los Papeles de Natalio Rivas, conservados en la Real Academia de la Historia, constituyen un formidable ejemplo al respecto, desde la perspectiva de quien fue Subsecretario de Presidencia, de varios ministerios y destacado dirigente del Partido Liberal en la segunda fase de la Restauración.

Los trabajos del profesor Ángel Bahamonde fueron pioneros en el estudio del desenvolvimiento de las diversas clases sociales madrileñas, desde la alta nobleza a la burguesía financiera, para llegar a las clases populares de Lavapiés o Ribera de Curtidores y Arganzuela. Una buena muestra fue su tesis doctoral El horizonte económico de la burguesía isabelina, dirigida por José María Jover Zamora, Universidad Complutense de Madrid, 1981; así como su obra precursora, escrita en colaboración con Julián Toro Mérida, Burguesía, especulación y cuestión social en el Madrid del siglo XIX, Madrid, Siglo XXI, 1978.

Una primera aproximación a esta hipótesis puede verse en mi aportación a la obra colectiva La sociedad urbana en el Madrid contemporáneo, Luis Enrique Otero Carvajal y Jesús A. Martínez Martín (eds.), Madrid, Los Libros de la Catarata, 2018, págs. 89-102. 
prácticamente en el tiempo con el inicio del trazado de la red de ferrocarriles y el tendido del telégrafo eléctrico. El imperativo que sigue la ubicación de la vieja prensa sería, pues, el de la cercanía al Poder político, en su sentido más estricto. En el caso de Madrid, radicado en torno a un eje que se vertebra entre los polos del edificio de la Carrera de San Jerónimo y el Palacio Real. Así pues, el primer foco de irradiación de la Prensa -y del negocio conexo de la imprenta- tenía su histórico centro de gravedad en la Puerta del Sol y los alrededores de la Carrera de San Jerónimo. Además, los prácticamente incontables pequeños periódicos, políticos o de partido, vinculados a los personajes notables y a las diversas familias políticas, integrantes de los partidos del sistema, que carecían de imprenta propia, también encuentran su ecosistema más propicio en esta área de la ciudad. Un entorno en el que proliferan los negocios de impresión, acordes con la elevada demanda de una ciudad cortesana y de sus servicios conexos. Unos talleres de imprenta que -hay que recordar- fueron uno de los grandes puntales del relativamente tardío proceso de industrialización madrileño ${ }^{7}$.

En este sentido industrial, había también claramente dos modelos alternativos y contrapuestos: una vieja prensa, que no disponía de talleres de imprenta propios, frente a la nueva, que contará con grandes edificios, construidos ex profeso, distribuidos en tres niveles, de acuerdo a la clásica trilogía de actividad profesional: talleres, redacción y oficinas para la Administración, Gerencia y Dirección. Una nueva prensa impulsada, además, por grandes magnates industriales, relevantes personalidades con una concepción moderna del negocio y una sólida formación académica y profesional. Con personalidades de tan amplia y brillante trayectoria como Nicolás María de Urgoiti (1866-1951) o Luis Montiel y Balanzat (1884-1976). Este segundo modelo es el que corresponde a las nuevas empresas periodísticas -surgidas a comienzos del siglo XX-que marcan importantes distancias empresariales y geográficas en el espacio urbano.

$\mathrm{Y}$ es que la expansión de las ciudades hizo que la esfera privada y pública en la sociedad urbana fuera diferenciándose sensiblemente. El viejo Madrid burgués del XIX se vio rodeado de nuevas y populosas barriadas, a imagen y semejanza de ese océano suburbano que habían generado París y Londres en sus alrededores. La expansión urbana favoreció la aparición de nuevas propuestas de organización del espacio urbano, cuyas mayores expresiones fueron la construcción de la Gran Vía y la realizada por Arturo Soria, con su propuesta de Ciudad Lineal ${ }^{8}$.

La evolución de su implantación en el paisaje urbano es un proceso, por otra parte, lógico, dado que se trata de una ciudad como Madrid que se expande rápidamente y virtualmente inacabada, con un fuerte crecimiento de población, desde comienzos del siglo XX. Las grandes empresas periodísticas, nacidas en el primer tercio del siglo XX, buscan nuevos horizontes urbanos, en las cercanías del Ensanche, de los grandes Bulevares y del Barrio de Salamanca. Del mismo modo que van a ser exponentes de proyectos políticos que, al menos, se pretenden profundamente renovadores. Las renovadas empresas editoriales del siglo XX marcan, pues, orgullosamente - $\mathrm{O}$ arriscadamente, en expresión de José Ortega y Gasset- cierta distancia e independencia respecto al Palacio de las Cortes y el de Oriente, así como respecto a los consiguientes hábitos subsidiarios y prácticas arraigadas en la vieja prensa decimonónica.

La vieja prensa del siglo XIX -exponente a su vez de la vieja política, de la que habló Ortega y Gasset en su celebrada conferencia del Teatro de la Comedia de 23 de marzo de 1914- se localiza y tiene su centro de gravedad en el Distrito Centro, concretamente en los Barrios de Palacio, Embajadores, Cortes, Justicia, Universidad y Sol, en torno al gran eje transversal que discurre, a través de la calle Mayor, por la Puerta del Sol y la carrera de San Jerónimo, enlazando el Palacio Real y el del Congreso de los Diputados; siendo ambos lugares emblemáticos, espacios del poder político constitucional por excelencia, los auténticos epicentros y ejes gravitacionales. De modo que, para los pequeños y grandes periódicos políticos más tradicionales, la principal y casi única pauta de implantación parece ser, al menos inicialmente, la mayor cercanía posible al Palacio Real, la Puerta del Sol y la Carrera de San Jerónimo.

\section{EI modelo de la vieja prensa del siglo XIX}

El primer exponente y prototipo genuino del modelo clásico es el diario vespertino La Época: últimos telegramas y noticias de la tarde (1849-1936), el órgano por excelencia, durante su larga trayectoria, del partido conservador. Este periódico tenía la sede de su redacción y administración en un local de alquiler en la calle de la Libertad, número 18, bajo, en el Barrio de Justicia, Distrito Centro. Se trata de una corta vía -todavía existente con el mismo nombre- continuada por la calle del Marqués de Valdeiglesias, hasta la confluencia de Gran Vía y Alcalá. Una calzada -antes conocida como calle de las Torres- que recibiría el nombre del Marqués de Valdeiglesias desde 1902, precisamente, en honor de quien fue propietario y director de La Época, entre 1866 y 1887, el político -diputado a Cortes y consejero de Estado- y periodista madrileño Ignacio José

Las imprentas, la industria editorial y la prensa integraron el heterogéneo sector servicios, uno de los grandes puntales de la industrialización madrileña, como ha evidenciado la enciclopédica obra, dirigida por Jesús Martínez Martín, Historia de la edición en España, 1836-1936, Madrid, Marcial Pons, 2002.

Como ha señalado el profesor Luis Enrique Otero Carvajal, en "La sociedad urbana y la irrupción de la Modernidad en España, 1900-1936", Cuadernos de Historia Contemporánea, núm. 38, 2016, págs. 255-283. 
Escobar y López Hermoso (1823-24 de enero de 1887). A Escobar le fue otorgado por el monarca Alfonso XII, por los servicios prestados a la causa de la Restauración borbónica -bajo el ya referido liderazgo político e intelectual de Cánovas-, el título nobiliario de Marqués de Valdeiglesias, mediante real decreto de 17 de abril de 1879, publicado en la Gaceta de Madrid de 3 y 7 de mayo de 1879.

Este diario no tuvo sede ni imprenta propia durante la mayor parte de su historia. Sin embargo, la Casa de Imprenta y Tipografía Hijos de Manuel Ginés Hernández, en la que se imprimía, se encontraba prácticamente anexa, en la propia calle Libertad, número 16, duplicado. Se trasladaría definitivamente en 1918, en la que sería su última etapa -que llegaría hasta 1936-, ya con escasa relevancia editorial y considerado prácticamente como un periódico sapo -sin una fisonomía particular, una línea editorial al servicio del mejor postor y con financiación inconfesable-, a la calle de San Bernardo, número 78 -antiguo Palacio de Santa Marta-, en el Barrio de Universidad -todavía en el Distrito Centro-, donde ya contaría, finalmente, con servicios de impresión propios.

Su gran rival y antagonista político, al menos durante la era isabelina, el diario del partido progresista $L a$ Iberia: diario liberal de la mañana (1854-1898), tenía su sede, imprenta y oficinas en la calle de Valverde, número 16, bajo derecha, en el Barrio de Universidad, Distrito Centro. Como diario sagastino, sería un medio periodístico clave en la Revolución de 1868, pero experimentando desde entonces un imparable declive, aunque pervive hasta fin de siglo gracias a su íntima relación financiera con el Partido liberal progresista. Fundado por el malogrado político y periodista Pedro Calvo Asensio (1821-1863), tras su muerte pasó de facto a ser dirigido por el propio Sagasta.

No muy diferente sería, al menos desde el punto de vista de su ubicación espacial, la extensa trayectoria de La Correspondencia de España: diario universal de noticias. Eco imparcial de la opinión y de la prensa (18591925), el periódico que inauguraría el modelo de periodismo de empresa en España. Considerado el primer gran diario de información general con niveles masivos de difusión, fue el primero que superó -oficialmentelos diez mil ejemplares diarios. Se trata de un diario vespertino de carácter nacional, apodado como el gorro de dormir de los españoles, que se pretendía estrictamente informativo e independiente de los partidos políticos. Pese a su subtítulo - con alguna pequeña variación- de diario político independiente y de noticias, lo cierto es que, en su largo historial, se caracterizaría por ser muy afín al gobierno de turno y siempre receptivo a las subvenciones públicas, por lo que también sería motejado por sus rivales como el órgano ministerial de todos los ministerios.

Este diario estuvo situado, la mayor parte de su historia, en la conocida popularmente como Casa de $L a$ Corres, en la Calle del Factor, números 5 y 7, muy próxima al Palacio Real, en el Barrio de Palacio, Distrito Centro. Aunque, en sus inicios, también se ubicó, muy brevemente, en el pasaje de Matheu y en la calle Desengaño -muy cerca de la Puerta del Sol-y algo más de una década -en concreto entre 1862 y 1875-, en la calle del Rubio, número 23, en el Barrio de Universidad, Distrito Centro. Una sede en la que conseguiría un espectacular despegue y convertirse en el diario vespertino de mayor tirada a nivel nacional. Por ello, la calle llamada entonces del Rubio sería posteriormente rebautizada -a fines de 1894- como del Marqués de Santa Ana, en honor precisamente al gran éxito editorial protagonizado por su fundador, el político y periodista sevillano Manuel María de Santa Ana y Rodríguez-Camaleño (1820-Madrid, 11 de octubre de 1894), quien había obtenido el título de Marqués de Santa Ana -y el nombramiento de senador real-por su adscripción sin fisuras a la causa dinástica, en atención "a los servicios que viene prestando durante largos años en la prensa periódica en pro de los intereses morales y materiales del país", durante la Regencia de María Cristina de Habsburgo, mediante real decreto de 14 de octubre de 1889, publicado en la Gaceta de Madrid de 18 de octubre de 1889.

Cabe, además, a La Correspondencia de España el honor de haber sido "el primer periódico de Madrid que ha tenido como casa propia un aristocrático palacio". Este hecho habría sido posible porque "el periódico creció mucho, sobre todo después de la guerra de África y, cuando salió a la venta el palacio ducal de los Abrantes situado en la calle Mayor", fue adquirido por Santa Ana'. De este modo, coincidiendo con el inicio de la Restauración, el periódico se instaló en un lateral del Palacio de Abrantes, con acceso -entonces-a través de la calle Mayor, número 120, para instalarse, poco después, definitivamente, en 1883, tras finalizar las obras de la referida Casa de La Corres, en la contigua calle del Factor, números 5 y 7, casi esquina con la calle Mayor. El Palacio de Abrantes sería entonces vendido por Santa Ana al gobierno italiano, que lo convertiría en la sede de su Embajada. Más adelante, en la que sería su última etapa, en las primeras décadas del siglo XX, trasladará su departamento de administración a la calle del Arenal, número 1, principal, donde contaba con amplios ventanales a la Puerta del Sol, más cerca si cabe del tradicional mentidero de la Villa y Corte, manteniendo en la calle del Factor su imprenta, redacción y oficinas.

También sigue un patrón muy parecido el progresista El Imparcial: diario liberal (1867-1933) que será considerado el medio de referencia nacional en las últimas décadas del siglo XIX. Después de varios cambios y traslados de sede en sus inicios, siempre en el entorno y equidistante del Palacio Real -Calle de Oriente, 3-,

Según el relato del célebre periodista José Gutiérrez Abascal, Kasabal (1852-1907), en "Los periódicos de Madrid", Blanco y Negro, 4 de febrero de 1899 . 
o de la Puerta del Sol y el Palacio del Congreso -Plaza de Matute, 5- se instalará en la calle de Mesonero Romanos, número 31, también junto a la Puerta Sol, donde radicará desde 1889 hasta 1913. En concreto, el 12 de febrero de 1913 El Imparcial pasaría a la que iba a ser su sede definitiva, en la calle del Duque de Alba, número 4, en el Barrio de Embajadores, Distrito Centro. Se ubicaba en una calle que iba -entonces- desde la Plaza del Progreso, después de la Guerra rebautizada como de Tirso de Molina, hasta la Plaza de Nicolás Salmerón, renombrada en 1941 como de Cascorro. El Imparcial, casa solariega de la familia Gasset, se trasladaba debido a una expropiación forzosa provocada por las emblemáticas obras modernizadoras de la Gran Vía. El 1 de abril de 1910 -tres días antes de la inauguración oficial de las referidas obras- el diario El Liberal anunciaba que la empresa Sociedad Editorial de España había "adquirido en pública subasta, y en el tipo de licitación, por 133.913,10 pesetas, el solar, propiedad de la Villa, sito en la calle del Duque de Alba, número 4. Tiene este solar 578 metros cuadrados, o sea 7.440 pies cuadrados, y 24 metros de fachada. En este solar, vecino a la casa del Heraldo de Madrid, se propone la Sociedad Editorial construir, lo más pronto posible, un edificio para instalar la redacción, administración, oficinas y talleres de El Imparcial". Con anterioridad, en 1902, se había frustrado un intento de fusión de El Imparcial con la revista Blanco y Negro ${ }^{10}$. Por fin, después de diversas vicisitudes, estuvo en condiciones de construir su propio edificio, una auténtica Casa-Palacio ${ }^{11}$ proyectada en 1911 por el arquitecto Daniel Zavala Álvarez. Sobre un solar irregular, se establecieron las diferentes secciones. En la parte exterior, con fachada a la calle Duque de Alba, número 4, se ubicaron las oficinas de administración, dirección y redacción. Detrás, en torno a un patio de grandes dimensiones, se situaron los talleres de composición. En el mismo solar, pero con acceso a través de la contrapuesta calle Colegiata, número 7 , se situaban entonces las oficinas y talleres de su correligionario de la noche Heraldo de Madrid.

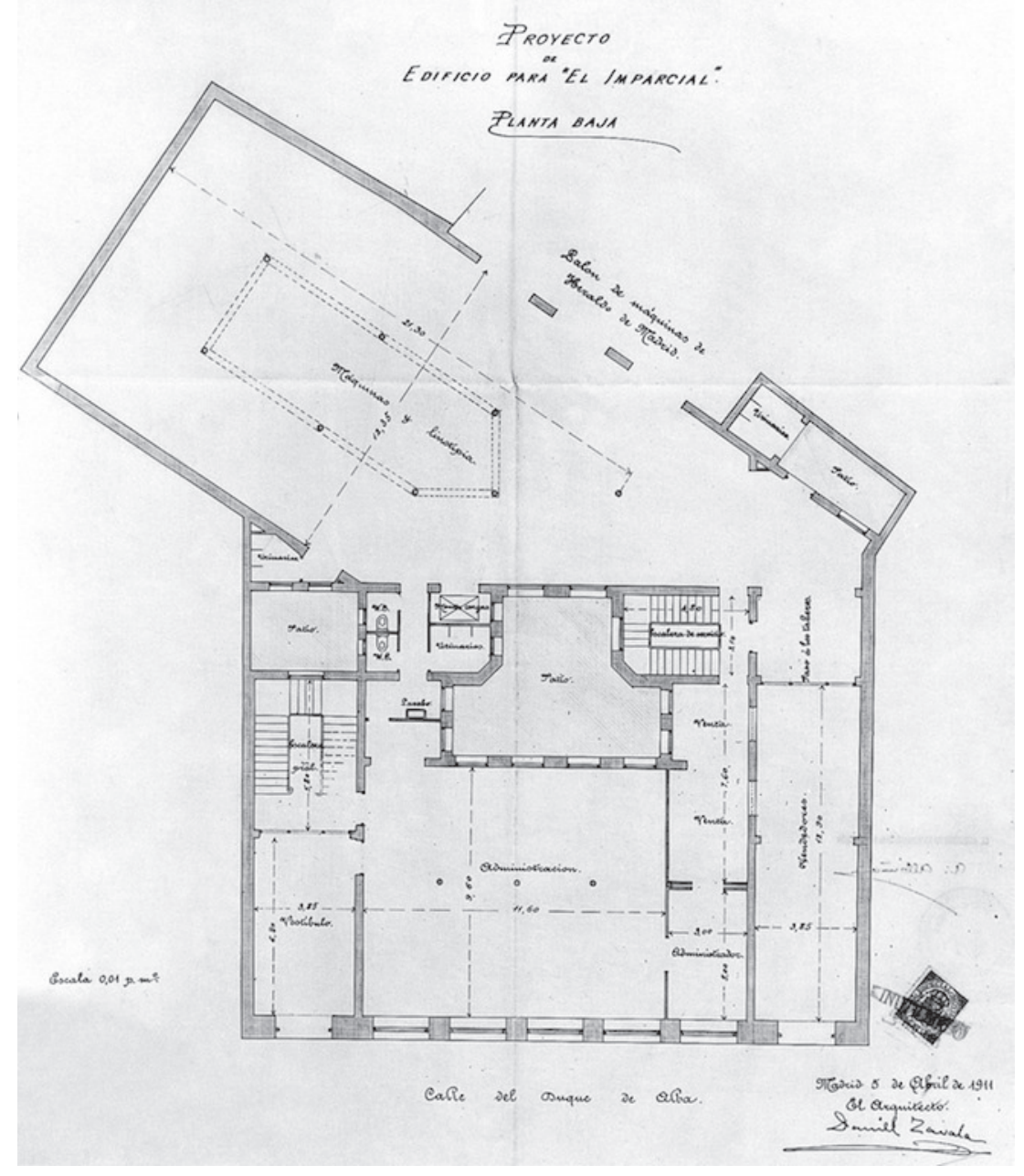

Plano de El Imparcial en la calle del duque de Alba, 4. Nótese la ubicación en el mismo solar, pero con acceso desde la paralela calle de la Colegiata, del diario vespertino Heraldo de Madrid.

Fuente: Colegio Oficial de Arquitectos de Madrid. Reproducido en https://artedemadrid.files.wordpress.com/2013/12/ plano-d-zavala1.jpg

10 Los Estatutos de la non nata Sociedad El Imparcial-Blanco y Negro pueden consultarse en los Papeles de Ortega Munilla, conservados en el Archivo de la Fundación Ortega y Gasset-Gregorio Marañón.

11 Recientemente rehabilitada y puesta en uso como espacio de ocio y servicios de restauración. 
El propietario y director de El Imparcial, el madrileño Rafael Gasset y Chinchilla (1866-1927), no aceptaría un título nobiliario, ofrecido insistentemente por Alfonso XIII, en coherencia con la línea editorial de liberalismo progresista y heredero de la Institución Libre de Enseñanza de su diario. Sin embargo, sí que llegaría a ser ministro en nueve ocasiones -como auténtico apóstol y profeta de la política hidráulica- y mantener una relación muy cercana con el Rey, entre 1900 y 1923, al frente del recién creado -16 de abril de 1900- Ministerio de Agricultura, Industria, Comercio y Obras Públicas que, desde 1906, retomaría su antigua denominación de Fomento ${ }^{12}$.

En idéntica línea empresarial cabe situar el recorrido del diario El Liberal (1879-1939), iniciativa del incansable promotor editorial, político y periodista Miguel Moya y Ojanguren (1856-1920) ${ }^{13}$. La salida de El Liberal fue resultado de una escisión ideológica por la izquierda por parte de un grupo de redactores de $E l$ Imparcial, cuando el diario de los Gasset decide aceptar el sistema dinástico. Se distinguió por su orientación de republicanismo moderado y su apertura a un público menos burgués que su matriz. Tuvo su sede editorial en la calle del Marqués de Cubas, números 5 y 7, en las cercanías del Congreso de los Diputados, en el Barrio de Cortes, Distrito Centro. Si bien es cierto que la ubicación de las oficinas y redacción de El Liberal estuvo, con anterioridad, algún tiempo en la calle de la Almudena, número 2 -muy cerca de la ya mencionada calle del Factor, en el Barrio de Palacio-, su gran sede histórica, la llamada Casa de El Liberal -y, luego, del Trust-, estuvo radicada, desde junio de 1895, en la calle del Marqués de Cubas, números 5 y 7 . Hay que recordar, por otra parte, que el nombre de Marqués de Cubas $^{14}$ es el que recibiría, el 1 de junio de 1900, la anteriormente conocida como la calle del Turco, cargada de resonancia histórica por haber sido escenario del magnicidio del general Prim. En efecto, la mudanza al nuevo edificio tuvo lugar durante los meses de mayo y junio de 1895. Se inauguró oficialmente el 24 de junio. Era un hermoso y suntuoso palacete, situado a espaldas del Banco de España, semiesquina con la calle de Alcalá. Ubicado, por tanto, en el lugar de más bullicio social de Madrid, donde estaba la mayor concentración de cafés tertulia y teatros, a un paso de la Puerta del Sol y del Palacio del Congreso de los Diputados. Su amplio y espléndido interior fue diseñado y ornado por el afamado arquitecto, pintor y escultor Arturo Mélida (1849-1902). "Tan vastas oficinas -refería entonces la revista La Ilustración Española y Americana - son necesarias a un periódico que tira ordinariamente más de cien mil números, que en ocasiones extraordinarias ha llegado a pasar de los doscientos mil, y que da ocupación en sus talleres a más de cien operarios. Los repartidores en Madrid son ciento treinta, y los corresponsales en provincias más de novecientos"15. Un auténtico poder fáctico, como sería -desde su constitución en mayo de 1906 por Miguel Moya- la Sociedad Editorial de España, se encontraba, pues, situado a escasos cientos de metros del Palacio del Congreso.

También en el mismo molde hay que encajar la intrahistoria del siempre muy popular diario vespertino Heraldo de Madrid (1890-1939). Fundado como El Heraldo de Madrid por el novelesco personaje e inquieto empresario, político y periodista Felipe Ducazcal (1845-1891), el 2 de mayo de 1893 perderá el artículo de su título, tras ser adquirido y refundado por el político liberal José Canalejas (1854-1912), convirtiéndose desde entonces en órgano del Partido Liberal, dentro de la tendencia demócrata y anticlerical de su propietario. Con su refundación, no solo perdería el determinante inicial sino que cambiaría radicalmente de tamaño y forma, para convertirse -según sus palabras- en "el periódico mayor de España [con mayúsculas y negrilla en el original], el de mayor tamaño y de más lectura, no sólo en relación a los de nuestro país, sino también comparado con muchos del extranjero". En cuanto a la instalación de los talleres, "se había propuesto la empresa llevarla a efecto en el suntuoso local de la calle de Sevilla que ocupan las oficinas del Banco General de Madrid, y a ese fin entabló gestiones para el arrendamiento del mismo; pero no habiendo sido posible obtener la autorización precisa para instalar allí máquinas y motores, y no queriendo alejarnos del centro de la capital, residencia obligada de todo periódico que quiera aprovechar bien hasta los minutos, hemos tomado para nuestros talleres la casa de la calle de la Reina, número 8 [una corta vía del Barrio de Justicia, Distrito Centro], contigua a la calle del Clavel, y emprendido en ella las reparaciones y obras necesarias, que terminarán dentro de pocos días"16.

El 1 de junio de 1895 se trasladaba, también de alquiler, a la antigua casa del Marqués de Villamejor -quien había decidido trasladarse entonces a su monumental nuevo palacio del Paseo de la Castellana, número 3-, en la calle de Barrionuevo, número 12 -que sería renombrada como del conde de Romanones desde 1 de junio de 1899-, siempre cerca de la Puerta del Sol, para pasar, el 20 de diciembre de 1902, a disponer de casa propia en un edificio principal de la contigua calle de la Colegiata, número 7, en el Barrio de Embajadores, Distrito

Para la labor de Rafael Gasset al frente del ministerio de Fomento y de su empresa periodística, véase mi obra Prensa y politica en la España de la Restauración. Rafael Gasset y 'El Imparcial', Madrid, Biblioteca Nueva, 1999 y 2008.

13 Véase la biografía de Margarita Márquez Padorno, Miguel Moya Ojanguren (1856-1920): talento, voluntad y reforma en la prensa española, Madrid, Ediciones APM, 2015.

14 En honor del recientemente fallecido arquitecto, prestigioso político y efímero alcalde conservador, Francisco de Cubas y González-Montes (18261899).

8 de noviembre de 1895, "La Casa de El Liberal".

6 Todas las referencias en "Nuestras reformas. Desde mañana", El Heraldo de Madrid, 1 de mayo de 1893. 
Centro. Aquí estaría su sede hasta fines de 1922, en la parte opuesta -como ya se ha indicado- del mismo solar que ocuparía la sede de El Imparcial desde febrero de 1913.

Una singularidad de este diario, en el espacio madrileño, importada al gusto de París -y muy acorde con su carácter popular y vespertino-, fue el que contara con un famoso Salón del Heraldo, en la calle de Alcalá, número 18, de nuevo muy cerca de la Puerta del Sol, esquina con la calle Sevilla, concebido como un lugar de encuentro y espacio de sociabilidad con sus numerosos lectores y en el que, desde 1897, tuvieron lugar incluso pioneras proyecciones cinematográficas ${ }^{17}$. Además, "en aquel sitio, centro de la capital y paso continuo de sus habitantes", el diario contaba con "las oficinas de publicidad, un despacho de administración para suscripciones de Madrid, provincias y extranjero, así como para toda clase de reclamaciones, y un gabinete de redacción destinado a los trabajos de última hora"18.

También en el Distrito Centro de Madrid se ubicó la sede del diario republicano progresista El País (18871921), considerado medio de referencia en el poliédrico universo republicano. En concreto, estuvo, durante la mayor parte de su existencia, en la calle de la Madera, número 8, en el Barrio de Universidad, en su origen también conocido como Barrio de Maravillas. Se trata de una calle de oficios tradicionales, entre los que ocuparía un lugar destacado el de la imprenta y la prensa, con la subsiguiente vida bohemia periodística, característica del barrio durante el siglo XX. El País fue un diario politizado en extremo, plenamente representativo de las peores prácticas de la vieja prensa y con una financiación, cuando menos, de origen bastante turbio. De hecho, su fundador, el matemático, periodista y político Antonio Catena (1840-1913), había sido promotor de un casino y casa de juego en las inmediaciones de la Puerta del Sol, concretamente en la calle Esparteros ${ }^{19}$.

\section{El patrón urbano de referencia para la prensa del primer tercio del siglo XX}

Muy diferente es el modelo de implantación urbana de la nueva prensa del siglo XX. Se trata de grandes empresas periodísticas, constituidas como Sociedades Anónimas, que se van alejando del Centro histórico hacia el Ensanche urbano, asentándose en los nuevos barrios del Norte de la ciudad.

El camino lo había abierto el lanzamiento, el 25 de diciembre de 1869, de la suntuosa revista semanal $L a$ Ilustración Española y Americana: periódico de ciencias, artes, literatura, industria y conocimientos útiles (1869-1921) por el editor gaditano Abelardo de Carlos y Almansa (1822-1884). Su salida marcó un hito en el mundo editorial madrileño ${ }^{20}$, el de la consagración del periodismo ilustrado y gráfico que introduce el elemento informativo de actualidad en la prensa, como líder indiscutible hasta la última década del siglo XIX en su segmento editorial. La ubicación de la sociedad editora tuvo un periplo ciertamente accidentado y rocambolesco, hasta que pase definitivamente, en 1882, a contar con imprenta propia en el monumental Establecimiento Tipográfico Sucesores de Rivadeneyra, constituyendo una de las principales y más emblemáticas empresas tipográficas de la Edad de Oro del periodismo español ${ }^{21}$. Constituida, desde sus inicios, como impresores de la Real Casa, en la Cuesta de San Vicente -entonces Paseo-, número 20 y radicada en el perímetro exterior del Barrio de Palacio, Distrito Centro. Estratégicamente situada, en consecuencia, frente a uno de los accesos laterales del Palacio Real y en las inmediaciones de la Estación del Norte, eje viario y núcleo neurálgico de la Compañía de los Caminos de Hierro del Norte de España. Además, aunque la redacción y talleres estaban en la cuesta de San Vicente, contaba también con oficinas comerciales y de administración en la más que céntrica calle de Carretas, número 12, principal.

La empresa denominada Establecimiento Tipográfico de los Sucesores de Rivadeneyra se constituiría en julio de 1882 -según su propia descripción- como un gigantesco "establecimiento tipográfico de nueva construcción y rival de sus similares extranjeros, donde veinte máquinas de imprimir y trescientos operarios, circuidos por una serie de edificaciones urbanas que el habitante de la corte puede contemplar en la Cuesta de San Vicente, constituyen una colonia industrial como rara vez se ha imaginado entre nosotros"22. En efecto, desde sus inicios fue considerado como "uno de los mejores periódicos ilustrados del mundo por su texto notable y escogido y por sus grabados artísticos, correctos y entonados", puesto que, en todos los elementos, "edificio, organización, maquinaria, material, disposición, aseo, limpieza, rapidez en la ejecución, perfección en la obra ejecutada", así como "en todas partes se ve, o se adivina, la mano inteligente de los Sres. de Carlos (padre e hijo), que deben citarse como modelos de industriales distinguidos y amantes muy verdaderos de los progresos de su patria. Y bien lo han probado; ahí están sus hechos" ${ }^{23}$.

\footnotetext{
Julio Montero y José Cabeza, Por el precio de una entrada: estudios sobre historia social del cine, Madrid, Rialp, 2006, pág. 34.

"A nuestros lectores", Heraldo de Madrid, 1 de junio de 1895.

Véase la referencia en El Motín, 8 de agosto de 1891, "Sentencia esperada".

Pese a que era, al mismo tiempo, una publicación sucesora de El Museo Universal (1857-1869), heredera a su vez del pionero Semanario Pintoresco Español (1836-1857) y de la revista La Ilustración (1849-1857).

Véase Miguel B. Márquez, “Abelardo de Carlos y la Ilustración Española y Americana”, en Ámbitos, núm. 13-14, 2005, págs. 185-209.

La Ilustración Española y Americana, 8 de abril de 1884, "D. Abelardo de Carlos", necrológica por José de Castro y Soriano.

23 En palabras del reputado hacendista Juan Navarro Reverter (1844-1924), en "La imprenta de la Ilustración”, La Ilustración Española y Americana, 30 de julio de 1882 .
} 
Sin embargo, hasta llegar a este celebrado momento, la intrahistoria de esta empresa había sido muy complicada. La revista había comenzado su recorrido histórico en la Imprenta de Gaspar y Roig, en la calle del Príncipe, número 4. Para ello, "lo primero de que se la dotó fue de una máquina magistral para la perfecta impresión de los grabados". Sin embargo, "la liquidación de aquella Casa le conminó prematuramente a crear, desde el número VII (25 de marzo de 1870), una imprenta propia, en la calle del Arenal, número 16; pero reconociéndola aún insuficiente, a pesar de haber traído del extranjero al conductor de máquinas Mr. Schweizer, desde el número 21, correspondiente al 25 de septiembre del mismo año, se trasladó al nuevo edificio que el laborioso tipógrafo D. Tomás Fortanet, ayudado de los conocimientos adquiridos en Francia, Inglaterra, Bélgica y Alemania, por su hijo don Joaquín, acababa de construir en la calle de la Libertad". Aunque, "en este establecimiento indudablemente hubiera arraigado definitivamente, pues en él depositó todo el gran material de máquinas, fundiciones y talleres, que poco a poco iba enriqueciendo", esta iniciativa quedaría muy pronto frustrada por "la desgracia del desplome de una parte de la nave de trabajo, al mediar el día 14 de octubre de 1872, dejando bajo los escombros ocho operarios, de los cuales tres muertos, y horriblemente destrozadas las máquinas”. Así pues, la Imprenta de Tomás Fortanet, situada en la calle de la Libertad, número 29, concretamente entre las calles de la Libertad y del Soldado -renombrada desde 1894 como de Barbieri- sufrió una terrible catástrofe. "La Casa Imprenta del Sr. Fortanet, parte de ella en construcción -refería El Imparcial-, se ha venido a tierra en ocasión en que los operarios del establecimiento, en número de doce a catorce, se hallaban trabajando... sepultados bajo los escombros". Así que "el edificio por la parte de la calle del Soldado, que era donde estaban las cajas y máquinas de la imprenta, ha venido todo al suelo, conservándose en pie la parte en que habitaba la familia. Las pérdidas son considerables, puesto que han quedado en bastante mal estado siete máquinas, una de ellas de bastante valor" ${ }^{24}$. En aquella dramática tesitura, la imprenta que había pertenecido al recientemente fallecido editor Manuel Rivadeneyra ${ }^{25}$, establecida en la calle del Duque de Osuna, número 3, en el entorno de la Plaza de España - entonces conocida como de San Marcial-, sería la solución, para salir del "conflicto momentáneo, y aunque el periódico continuó llevando el pie de imprenta de Fortanet en los números XLy XLI siguientes, no solo quedó establecida ya de una manera permanente en el nuevo establecimiento, sino que allí hicieron relaciones de intimidad que se convirtieron en participación y luego en completa adquisición de aquel ya renombrado establecimiento tipográfico". De hecho, Manuel Rivadeneyra había fallecido el 31 de marzo de 1872 y su viuda decidiría vender el establecimiento a Abelardo de Carlos, pasándose a denominar desde entonces Sucesores de Rivadeneyra. Desde este enclave, "años después surgió en la mente de de Carlos la construcción de un edificio de nueva planta, y dotado de todos los elementos que constituían la última palabra de los adelantos del arte, proyecto que realizó en la Cuesta de San Vicente, núm. 20, el Establecimiento Tipográfico de Sucesores de Rivadeneyra. En él está desde 1882 la morada oficial de La Ilustración Española y Americana y de La Moda Elegante" ${ }^{" 26}$. Sin embargo, Abelardo de Carlos Almansa, su fundador, editor y director, apenas tendría tiempo para disfrutar de su gran éxito editorial, al fallecer el 8 de abril de $1884^{27}$.

El 10 de mayo de 1891 nace la publicación que desbancaría ese liderazgo. Se trata de Blanco y Negro: revista ilustrada -editada hasta el año 2000-, fundada por el empresario sevillano Torcuato Luca de Tena y Álvarez Ossorio (1861-1929). En palabras de su promotor, recordando sus inicios, "aquel Blanco y Negro se imprimió durante tres años en la Casa Rivadeneyra, precisamente". Por sus elevados costes, "Blanco y Negro se vendía a quince céntimos. Más tarde, instalé una imprenta en la calle de Claudio Coello, y desde esa imprenta vinimos a esta Casa de $A B C$, cuya primera piedra se colocó el 21 de septiembre de $1896^{\text {"2 } 28}$. Su primera instalación propia estuvo situada, efectivamente, en la calle Claudio Coello, número 41, en el Barrio de Recoletos, Distrito de Salamanca. Comenzaba el trascendental año de 1898 en el número 104 de la misma calle y con el membrete de "periódico ilustrado de mayor circulación de España", al precio de veinte céntimos, igual que su gran competidora. En febrero de 1899 se traslada a su histórica sede, la que sería conocida primero como Casa de Blanco y Negro -y enseguida de $A B C$-, en un palacete de estilo neoplateresco construido en la calle Serrano, número 55, en el Barrio de Recoletos, Distrito de Salamanca, en la que ha sido su gran sede hasta 1989. En el número especial de Blanco y Negro -de 4 de febrero de 1899-dedicado a su inauguración, se afirmaba que los viejos periódicos decimonónicos, concebidos como armas políticas, "cuidaban poco de la

Según relato de El Imparcial, 15 de octubre de 1872, "Sección de noticias", pág. 3.

25 Manuel Rivadeneyra y Reig (Barcelona, 1805-Madrid, 31 de marzo de 1872), tras hacer fortuna en Chile, se establecería en Madrid para editar la monumental Biblioteca de Autores Españoles (1846-1888). Para ello, puso en marcha la empresa editorial Imprenta y Estereotipia de Manuel Rivadeneyra.

26 Todas las referencias, en La Ilustración Española y Americana, "La Imprenta", 22 de diciembre de 1907; número especial dedicado al 50ªniversario de la revista, incluyendo en la onomástica a su precursora El Museo Universal.

27 Desde 1881 hasta 1898 la empresa fue dirigida por su hijo mayor, Abelardo José de Carlos Hierro (1848-1910), a quien sucedió su cuñado Alejandro Moreno Gil de Borja (1850-1931). Ya en la segunda década del siglo XX, en plena decadencia, por la competencia de otros medios, tras la sustitución de los clásicos grabados por las fotografías, sería adquirida en 1914 por Rafael Picavea, propietario de El Pueblo Vasco, quien contrató a Wenceslao Fernández Flórez como redactor jefe. En 1919 -como se verá más adelante- pasaría a manos del editor Luis Montiel.

28 Entrevista en la revista Estampa, número 1, 3 de enero de 1928, "Creadores de prensa. Don Torcuato Luca de Tena, fundador de Blanco y Negro y $A B C$ ”, por Antonio G. de Linares. Se le preguntaba, además, al empresario sevillano si “¿ha ganado usted mucho dinero con Blanco y Negro? — Mucho... Bástele saber que $A B C$ me costó, en los diez y ocho primeros meses de su publicación, ochocientas mil pesetas, y que fue Blanco y Negro quien pagó todo esto y sostuvo al nuevo periódico hasta su consolidación... Hoy paga esta casa un millón de pesetas de jornales, al año...”. 
parte material de las publicaciones y para instalar la redacción se elegía una casa cualquiera, en cuya habitación principal se colocaba una gran mesa de pino rodeada de algunas sillas de Vitoria". Según José Altabella, la mejor muestra de su gran éxito era precisamente que "nació en imprenta ajena y pronto la tuvo propia", ya que "nació en un piso alquilado y a los pocos años poseyó el primer Palacio propio que poseyó una revista española" ${ }^{29}$. Contaba, además, con una oficina en París, al igual que la que pronto sería su gran rival, la revista Nuevo Mundo.

El éxito de este semanario gráfico discurre prácticamente en paralelo al que será su inmediato gran competidor, Nuevo Mundo: crónica general de la semana, informaciones políticas, noticias comerciales (1894-1933), iniciativa del editor hispano-cubano José del Perojo y Figueras (1850-1908), quien figuraba como oficialmente como director político de la publicación. Nuevo Mundo sería, por su parte, la publicación favorita de la burguesía progresista, por lo que protagonizaría una gran rivalidad ideológica y comercial que se mantendrá en las primeras décadas del siglo XX. Tuvo su primer domicilio social no muy lejos de su rival, en la calle Jorge Juan, número 6, en el Barrio de Recoletos, Distrito de Salamanca. Comienza el siglo XX con el subtítulo de "periódico ilustrado de mayor circulación de España" y con domicilio en Santa Engracia, 57, en el Barrio de Trafalgar, Distrito de Chamberí. En 1908 la Imprenta y Fotograbado de Nuevo Mundo se instala, con el nuevo subtítulo de "noticias y crónicas", en un monumental edificio modernista de nueva planta, construido en la calle de Larra, número 8, obra del arquitecto municipal madrileño Jesús Carrasco-Muñoz y Encina (1869-1957) y ubicado en el límite del Barrio de Justicia y el nuevo Ensanche de los Bulevares. En ese mismo momento, sin embargo, Perojo fallecía de forma repentina en su escaño del Congreso de los Diputados, concretamente en la tarde del 17 de octubre de 1908, a la edad de cincuenta y ocho años. "El fundador de Nuevo Mundo -refería su semanario- ha muerto cuando el periódico, su obra favorita, acababa de instalarse, con toda esplendidez, en su nueva casa, que por sí misma es la prueba más patente y tangible de lo que son capaces de crear el trabajo y la constancia. El edificio, recién construido y no terminado aún en algunos detalles interiores, ocupa un solar de unos once mil pies cuadrados en la calle de Larra, número 8, a muy pocos pasos de la calle de Sagasta, que es una de las más amplias y hermosas del Madrid novísimo. Consta de tres plantas; el sótano; un piso al nivel de la calle y el principal". Por si fuera poco, "el sótano, palabra que en este caso expresa únicamente la posición, porque es amplísimo y claro, coge toda la extensión del solar, y tiene entrada aparte desde la calle, por una escalera especial, sirviéndole de vestíbulo un patio. Por éste pueden, mediante una grúa, descargarse las balas de papel y cargarse en los carros los paquetes en que los ciento veinte mil números de Nuevo Mundo salen semanalmente, en su mayoría con destino a las estaciones ferroviarias" ${ }^{30}$, a las que tenía fácil acceso gracias a su privilegiado emplazamiento junto al Ensanche. De hecho, la multitudinaria comitiva fúnebre de Perojo, camino del cementerio de la Almudena - a través de las calles de Sagasta, Génova, Goya y Alcalá- "pasó por la calle de Larra, en donde se alza el nuevo y suntuoso edificio de Nuevo Mundo, que estaba cubierto con colgaduras de terciopelo negro franjeadas de oro"31.

Entre tanto, el enorme éxito de Blanco y Negro daba lugar al lanzamiento del formalmente revolucionario diario gráfico $A B C$ : crónica universal ilustrada, que nació como diario el 1 junio de 1905, tras dos años en pruebas. Haciendo gala de un ideario liberal conservador y, sobre todo, fervientemente monárquico, enseguida se convirtió, con enorme éxito, en el más eficaz defensor del proyecto de regeneración conservadora, la conocida como revolución desde arriba, de Antonio Maura. Su fórmula periodística era la misma que la de su matriz, la precursora revista Blanco y Negro, una presentación moderna y atractiva, con gran relevancia de la información gráfica. Su formato era rupturista con la tradición y pretendía -como su nombre indica- ser el inicio radical de un nuevo lenguaje y modelo integral de periodismo. En vísperas de su primer aniversario, además, se apuntó un gran éxito publicitario e informativo -que le proporcionaría un fuerte impulso mercantil-, al conseguir en exclusiva fotografías del atentado anarquista contra el cortejo nupcial de Alfonso XIII que tuvo lugar el 31 de mayo de 1906. En 1909 se crea, por iniciativa de su fundador, la sociedad anónima Prensa Española, empresa editora del diario y otras publicaciones afines, con un capital de tres millones de pesetas. El edificio -sede desde 1909 de la sociedad anónima Prensa Española- sería ampliado con un nuevo espacio arquitectónico, con fachada neomudéjar, hacia el paseo de la Castellana, en 1926. La Casa de $A B C$ se convertiría muy pronto en un lugar emblemático para las manifestaciones políticas, a favor o en contra de la Monarquía, por su estrecha vinculación a los intereses de la Casa Real. De hecho, poco antes del fallecimiento de su fundador -que se produjo el 15 de abril de 1929-, el monarca Alfonso XIII le otorgaba el título nobiliario de Marqués de Luca de Tena, "queriendo dar una prueba de Mi Real aprecio a D. Torcuato Luca de Tena Alvarez-Ossorio Reina y Pizarro", mediante real decreto de 4 de febrero de 1929, publicado en la Gaceta de Madrid de 6 de febrero de 1929.

En mayo de 1906, para contrarrestar este gran éxito periodístico, se constituye -una vez más, como reacción frente al éxito del gran competidor-el que sería su gran rival político y empresarial, la ya referenciada Sociedad Editorial de España. El Liberal de Madrid había contado, de la mano de Miguel Moya, desde su aparición,

Blanco y Negro, 7 de mayo de 1966. "Apunte biográfico de Blanco y Negro”, pág. 168.

Nuevo Mundo, "La Casa de Nuevo Mundo", número 772, 22 de octubre de 1908

El Imparcial, "Entierro del Sr. Perojo", 20 de octubre de 1908. 
con un público numeroso, fundamentalmente de carácter popular y progresista. Comienza el siglo XX en una sólida posición empresarial. En 1901 la empresa editora inicia un ciclo expansivo, lanzando cuatro diarios del mismo título en Barcelona, Bilbao, Sevilla y Murcia. A partir de este fuerte impulso, Moya promovió la constitución de la nueva empresa Sociedad Editorial de España, junto a El Imparcial de Rafael Gasset, para hacerse también, inmediatamente, con la propiedad del canalejista Heraldo de Madrid. Nace así una empresa de grandes dimensiones que, desde su ya mencionada sede en la madrileña calle del marqués de Cubas - prácticamente aledaña al Congreso de los Diputados- va a ejercer durante una década una influencia prácticamente ilimitada, como un auténtico poder fáctico, en la vida pública española.

Se configuran, pues, en la primera década del siglo XX dos grandes grupos periodísticos rivales, la Sociedad Editorial de España -más conocida como el Trust de la prensa liberal-y el conservador Prensa Española. Dos bloques periodísticos y políticos que iban a ser determinantes en los entresijos del devenir de la etapa final de la Restauración. A pesar de este duopolio, no se olvide, van a seguir siendo mayoritarios los numerosísimos pequeños periódicos políticos tradicionales que carecen de talleres e imprenta propia.

El Trust iniciaba su andadura con un propósito político - no confesado abiertamente- de unificar las tres grandes familias ideológicas del Partido Liberal: el regeneracionismo de escuela y despensa, postulado por Segismundo Moret - muy vinculado a las ideas de la Institución Libre de Enseñanza- y por Rafael Gasset, propietario de El Imparcial, apóstol de la política hidráulica costiana; el liberalismo socializante y reformista de Canalejas, desde las páginas del Heraldo, con sus ingredientes de anticlericalismo de la III República francesa y del liberalismo radical británico del primer ministro David Lloyd George; y, finalmente, el liberalismo más clásico, proclive a comenzar la regeneración por la vía del cambio político, empezando por cambiar la cúspide del sistema, en forma de republicanismo posibilista, de Miguel Moya y El Liberal, ligado a las figuras políticas de Eugenio Montero Ríos y de su yerno, Manuel García Prieto. Un bloque de la prensa liberal cuya argamasa era, en aquella coyuntura, precisamente el lema de ¡Maura, no!, pero que, con Maura fuera de juego, se diluiría de inmediato. De hecho, la pérdida de la confianza regia por parte de Antonio Maura y la posterior llegada de José Canalejas a la jefatura del Gobierno serían el fruto de un contexto explosivo, determinado por los sucesos de la Guerra de Melilla, la Semana Trágica y el fusilamiento de Francisco Ferrer, pero cuyo detonante adquirió la forma de una maniobra periodística, plasmada en el editorial de El Imparcial de 21 de octubre de 1909, con el título de “¿Pueden ser monárquicos los liberales?”, en el que, sin firma pero con la pluma de José Ortega Munilla $^{32}$, vicepresidente del Trust, se conminaba al monarca Alfonso XIII a elegir entre la estabilidad del sistema de turno o la permanencia de Maura al frente del Gobierno.

En todo caso, el experimento del omnipotente bloque periodístico liberal solo duraría una década, perjudicado por una suerte de leyenda negra que le acusaba de estar detrás de todas las crisis políticas del momento, al ser considerado, con buena parte de razón, como una especie de deus ex machina que todo lo movía en la sombra, como reconocería en abril de 1916 el propio diario El Imparcial, al anunciar su salida de la otrora todopoderosa Compañía Editorial ${ }^{33}$.

De nuevo, una vez más, de forma reactiva, en este caso contra la política anticlerical del gobierno de Canalejas sostenida por el bloque periodístico del Trust, nace el 1 de octubre de 1910 el diario El Debate: diario católico e independiente de la mañana (1910-1936). Los católicos más aperturistas, liderados por el futuro cardenal Ángel Herrera Oria (1886-1968) y la Asociación Católica Nacional de Propagandistas, deciden aceptar el liberalismo político y periodístico como una realidad insoslayable. Sin contar con una prensa propia, advierten indudablemente que no tendrían ninguna influencia en la esfera pública de la Restauración. El nuevo diario católico, durante su primera etapa, atravesó numerosas dificultades editoriales, al carecer de una sólida estructura empresarial e imprenta propia y ocupó diversas sedes, la más estable en la calle del Marqués de Cubas, número 3, curiosamente junto a la Casa de El Liberal. En enero de 1923 se instaló, mediante su adquisición, en la Casa Editorial que había sido del Heraldo de Madrid, en la calle de la Colegiata, número 7. Hasta 1932 no se inauguraría la que sería su sede histórica -y de la poderosa empresa Editorial Católica Sociedad Anónima-, en la calle de Alfonso XI, número 4, en el Barrio de los Jerónimos, Distrito de Retiro, junto al gran Ensanche del Barrio de Salamanca. Se tratará, además, del espacio que ocuparía durante décadas el conglomerado de organismos sociales de la Iglesia -fue sede también de la Conferencia Episcopal y actualmente lo es de la COPE-, marcando así distancias relativas del Distrito Centro, radicándose en el entorno de la Puerta de Alcalá y del Barrio de Salamanca.

También se aleja del Distrito Centro, en este caso hacia la calle Sagasta y los grandes Bulevares, el nuevo diario radical progresista El Sol (1917-1939). Para su edición, su promotor empresarial, el reputado industrial vasco Nicolás María de Urgoiti (1866-1951), utilizaría las modernas e imponentes instalaciones que habían pertenecido a la empresa Prensa Gráfica Sociedad Anónima, en la calle de Larra, número 8, que había adquirido en 1914. La iniciativa de la venta a la poderosa Papelera Española de Urgoiti, quien inyectaría grandes aportaciones de capital, había partido del economista Mariano Zavala (1865-1944), quien había sido fundador -con el malogrado editor José del Perojo- de Nuevo Mundo y era gerente de la sociedad anónima

Véanse los Papeles de Ortega Munilla, Fundación José Ortega y Gasset/Marañón.

"El Imparcial y la Sociedad Editorial de España", 27 de abril de 1916. 
Prensa Gráfica, desde su constitución en 1913, junto al polifacético periodista Francisco Verdugo Landi (18741959).

Desde 1915, por otro lado, Prensa Gráfica se trasladaría a una nueva y funcional sede, situada en el número 57 de la calle de Hermosilla, en el corazón del Distrito de Salamanca ${ }^{34}$. El Sol de Ortega y Gasset y Urgoiti, por su parte, saldría a la calle, desde la que había sido sede de la sociedad anónima Prensa Gráfica, en la calle de Larra, número 8, el 1 de diciembre de 1917, después de una azarosa prehistoria, en la que se había visto frustrado un intento de refundación de El Imparcial. Su logo, un gallo arrogante sobre una bobina de papel continuo, resultaba muy revelador de las ambiciosas intenciones, profundamente críticas y renovadoras del sistema político, que estaban detrás de sus impulsores. Los resultados económicos, sin embargo, no serían tan brillantes y exitosos como los intelectuales, lo que llevaría al lanzamiento el 1 de julio de 1920, en la misma sede editorial, del diario vespertino La Voz (1920-1939), con un tono mucho más ligero y popular que su hermano mayor.

\subsection{Un cambio superficial... para que todo siga igual}

Como excepción que confirma el modelo de implantación urbana de la nueva prensa del siglo XX, cabe calificar la salida a la calle de dos nuevas publicaciones que verán la luz en la tercera década del siglo XX. Con un accionariado opaco y poco confesable, reproducen los hábitos empresariales de la vieja prensa, aunque con formatos y contenidos adaptados a los nuevos tiempos. Se trata del diario de extrema izquierda La Libertad (diciembre de 1919-marzo de 1939), ubicado en la calle de la Madera, número 8 -aunque hasta octubre de 1922 utilizaría la imprenta de La Correspondencia de España en la calle Factor, 7-; así como, desde enero de 1922, el vespertino de extrema derecha Informaciones (enero de 1922-junio de 1983), en la vecina y adyacente calle de San Roque, por donde se entraba a la imprenta de La Libertad, ocupando ambos medios diversos accesos al mismo edificio de la Casa Editorial que había sido la sede del diario republicano progresista El País, entre 1887 y 1921, en el Barrio de Universidad, Distrito Centro.

Los promotores, en la sombra, de La Libertad eran el político liberal Santiago Alba (1872-1949), el empresario vasco Horacio Echevarrieta (1870-1963) -propietario de El Liberal de Bilbao- y el siempre controvertido y todopoderoso hombre de negocios mallorquín Juan March Ordinas (1880-1962), que actuaba como auténtico financiador y factótum desde la trastienda ${ }^{35}$. Alba y March también estuvieron detrás, a principios de 1922, del lanzamiento de Informaciones, que en 1925 pasaría a ser propiedad exclusiva del propio March, quien conseguía así disponer al mismo tiempo del control e influencia sobre un periódico de extrema derecha y otro de izquierdas. De este modo, ambos medios, en las antípodas ideológicas pero con el mismo propietario, compartían inmueble, aunque con entrada en el caso de Informaciones por la referida calle San Roque. Eduardo Haro Tecglen -en su libro de memorias El niño republicano ${ }^{36}$ - refiere así la pintoresca amalgama: "durante casi la mitad de los años de mi vida he ido a la calle de la Madera /calle san Roque: el mismo edificio... En ese edificio estuvieron los dos primeros periódicos de mi vida: La Libertad, donde trabajaba mi padre [Eduardo Haro Delage, subdirector]; Informaciones, que fue el mío. Los dos fueron de Juan March; uno de izquierdas, otro de derechas, para defenderse mejor". De hecho, se acusará repetidamente, por ello, al financiero de "jugar con varios naipes a la vez" y de "encender una vela a Dios y otra al diablo" 37 . La trayectoria de dos diarios, aparentemente tan contrapuestos en su ideología y línea editorial, como eran $\mathrm{La}$ Libertad e Informaciones, es totalmente singular e inclasificable, pudiendo ser calificada por ello como una suerte de nueva prensa en moldes viejos. Nacidos en las postrimerías del sistema turnista de la Restauración y, ocupando el mismo espacio urbano que había sido el del diario republicano El País -eximio representante del viejo periodismo decimonónico-, el diario La Libertad se mostraría siempre cercano a la extrema izquierda revolucionaria e incluso al partido comunista en la década de 1930; mientras que Informaciones, por su lado, se movería siempre dentro del espectro de la extrema derecha protofascista e incluso llegaría a ser financiado por la embajada de la Alemania nazi en Madrid. En el caso de La Libertad, la influencia de March no desaparecerá definitivamente hasta julio de 1934, cuando se hacía público el cambio de director y de propiedad de su empresa editora ${ }^{38}$ : March se había desprendido de sus acciones en mayo. El 14 de julio Antonio Hermosilla relevaría a Joaquín Aznar en la dirección del diario y el 6 de noviembre del mismo año se constituye su nueva empresa editora: Prensa Republicana Independiente, S.A.

\footnotetext{
34 Un nuevo espacio editorial en el que se elaborarían publicaciones como la veterana Nuevo Mundo (1894-1933); Mundo Gráfico: revista popular ilustrada (1911-1938), una de las revistas más asequibles y de mayor difusión dedicadas al fotoperiodismo; y la suntuosa La Esfera: ilustración mundial (1914-1931) que sería cabecera y referencia editorial del grupo, al menos hasta la salida de Crónica en noviembre de 1929.

Véase al respecto la excelente biografía de Mercedes Cabrera, Juan March (1880-1962), Madrid, Marcial Pons, 2011.

Madrid, Alfaguara, 1996, pág. 243.

María Cruz Seoane y María Dolores Saiz, Historia del periodismo en España 3. El siglo XX: 1898-1936, Madrid, Alianza Editorial, 1996 , pág. 348.

El periodista Antonio Hermosilla, su nuevo gerente y director, escribía al respecto que "la Prensa, la gran Prensa no puede ser órgano de nadie, sino reflejo de esa opinión nacional, crisol en que se funden todos los anhelos justos, retorta en donde se mezclan todas las inquietudes legítimas, fuente en que vierten todas las aguas puras de la conciencia colectiva". "La política y el periodismo. Los órganos de publicidad se deben exclusivamente a la opinión general del país. Por eso la Gerencia de La Libertad se funde desde hoy con la Dirección”, La Libertad, 14 de julio de 1934.
} 
Sigue también el mismo modelo de localización, característico de una suerte de superficialmente remozada vieja prensa, el diario La Tribuna. Diario independiente: información, literatura, ciencias, artes, deportes, teatros, modas (1912-1924), iniciativa del siempre polémico y venal periodista Salvador Cánovas Cervantes (1880-1949), que tenía su redacción, administración y talleres situados en la calle Jardines, 4, 6 y 8, en un singular edificio neomudéjar ${ }^{39}$ ubicado en el Barrio de Sol, Distrito Centro. La salida de este diario había sido posible gracias a su adscripción al maurismo. Una corriente disidente del partido conservador de la que se benefició para su financiación y de la que ejerció como portavoz más cualificado hasta el 28 de febrero de 1916, cuando sale a la calle -en una suerte de spin off-La Acción: diario de la noche (1916-1924), que ocupará su lugar como referente del maurismo. Su sede estaba en la carrera de San Francisco, número 13, en el Barrio de Palacio, Distrito Centro. Aparecía con el lema editorial, subrayado y con gran tipo de letra -en realidad, una especie de excusatio non petita acusatio manifesta- de que "este periódico, sin relación con los gremios políticos, tiene por único programa decir la verdad". En realidad, estaba impulsado por el -no menos controvertido e hiperactivo- periodista Manuel Delgado Barreto (1879-1936), en directa competencia por las subvenciones con La Tribuna de Cánovas Cervantes, que abandonará por ello su filiación maurista. Desaparecerá en mayo de 1924, por problemas económicos y, un año después, Delgado Barreto pasará a dirigir La Nación (1925-1936) que nace como órgano oficioso de la dictadura primorriverista, al que irán también la mayor parte de los redactores y colaboradores de La Acción.

El edificio de la calle Jardines, en el que se había editado La Tribuna, pasaría a ser sede de La Tierra (diciembre de 1930-junio de 1935), periódico también iniciativa de Cánovas Cervantes, con un historial inclasificable y con una leyenda negra de largo alcance historiográfico. El diario presumía de no ser "un periódico de empresa", puesto que "está escrito e inspirado únicamente por periodistas independientes". Por ello anunciaba, el 16 de diciembre de 1930, que nacía "para defender los altos intereses de la opinión pública a la que se consagrará por completo". La realidad era muy diferente. Según Antonio Elorza, el desprestigio del propietario de La Tierra, Cánovas Cervantes, periodista conservador pasado al anarquismo racial del Partido Social Ibérico, "era total entre quienes vivieron el período republicano. Le apodaban nini, ni lo uno ni lo otro". Y prosigue, al respecto, "entre otros testimonios orales que recibí al respecto, está el del político derechista Pedro Sainz Rodríguez, quien me contó... que la derecha monárquica subvencionaba en un sentido y en otro, a José Antonio y a La Tierra con tal de fastidiar a la República". Aún más, "lo precisa en su autobiografía Testimonio y recuerdos ${ }^{40}$ partiendo de la campaña sobre Casas Viejas: 'Esta campaña -se sabe ahora porque yo creo conveniente revelarlo- fue impulsada por las derechas... El señor Cánovas Cervantes, director y propietario del periódico, se citaba conmigo precisamente en la rinconada que hace el callejón de Arenal ya mencionado, enfrente de la librería de los Bibliófilos... Allí recibía Cánovas Cervantes un sobre en el que iban las directrices de la campaña, textos redactados por nosotros y una muestra de nuestro agradecimiento por esta colaboración política"' ${ }^{41}$. También Manuel Azaña tacharía al diario de Cánovas Cervantes de ser un libelo y de estar subvencionado por el banquero Juan $\mathrm{March}^{42}$. La Tierra publicó su último número el ocho de junio de 1935, probablemente por problemas económicos, falto de la necesaria publicidad y venta de ejemplares para su mantenimiento. Hay que volver a destacar, en todo caso, que se trataba de una nueva prensa tan solo en apariencia, una especie de vino nuevo en odres viejos, ya que va a mantener algunos de los peores hábitos y prácticas de la vieja. De hecho, su ubicación en pleno Distrito Centro de la capital parece ser una buena muestra de sus intenciones, por encima de las retóricas declaraciones de independencia en su cabecera.

\section{Conclusiones. Un impulso para la prensa madrileña desde la Ciudad Condal. La prensa se industrializa}

Entre tanto, el 19 de agosto de 1920 había fallecido en San Sebastián Miguel Moya Ojanguren, el gran promotor de la Sociedad Editorial de España. Su gerente, el economista y catedrático de la Escuela de Comercio Antonio Sacristán y Zavala (1871-1938), conseguirá, finalmente, una salida viable para una empresa muy endeudada y en situación ruinosa, inmersa en el laberinto de una tortuosa liquidación judicial: el traspaso, a fines de noviembre de 1922, de Heraldo y El Liberal a una nueva empresa, constituida a tal fin, la Sociedad Editora Universal (SEU), de los industriales químicos catalanes hermanos Manuel y Joan Busquets George, delegados y asociados para España de la todopoderosa Standard Oil de Rockefeller y grandes acreedores del Trust por la provisión de derivados del petróleo, especialmente de las tintas. En medio del farragoso pleito judicial por las deudas adquiridas, $A B C$ hacía pública la adquisición de ambos diarios por un millón de pesetas, con la intención de evitar "la confabulación que representan los señores Busquets" 29 de noviembre se daba a conocer que "se han reunido en junta general extraordinaria los accionistas de la Sociedad Editorial de España, para solucionar su situación y dar fin a los incidentes varios que en este último

Actual sede de la Oficina de Atención al Refugiado de la Comunidad de Madrid.

Barcelona, Planeta, 1978, pág. 246.

Antonio Elorza, "En torno a La Tierra", El País, 27 de febrero de 2007.

Seoane y Saiz, 1996, págs. 431-432.

"A los accionistas y acreedores de la Sociedad Editorial", 2 y 12 de noviembre de 1922. 
período le han afectado", aprobando "por unanimidad el convenio con los señores don Manuel y don Juan Busquets, a quienes agradeció sus actos y buenos propósitos, quedando autorizado el Consejo para formalizar el contrato con estos señores" $" 4$

Esas confabulaciones, de las que hablaba crípticamente $A B C$, aludían, sin duda, al trasfondo editorial de la nueva empresa, nacida con el acrónimo de SEU -Sede en catalán- que sería presidida efectivamente, a través de su consejo de administración, por Manuel Busquets George (1872-1955). Esta iniciativa obedecía, de hecho, a un ambicioso proyecto empresarial e intelectual diseñado por su apoderado en la operación, el prestigioso abogado, decano del colegio de abogados de Barcelona y periodista Amadeu Hurtado Miró (1875-1950), de establecer -literalmente- la Sede del catalanismo político y periodístico en Madrid. De la SEDE-Sociedad Editorial de España se pasaba a la SEU-Sociedad Editora Universal. De la sede castellana a la seu catalana, puesto que -en sus propias palabras- "no se trata de ir a hacer catalanismo a Madrid como si estuviéramos en Barcelona, sino de intervenir en la vida española pensando en catalán" ${ }^{45}$.

Los nuevos propietarios decidieron vender las instalaciones de Heraldo, en la calle de la Colegiata número 7, a la Editorial Católica - propietaria de El Debate- y ambos veteranos diarios pasaron a compartir sede en la vieja Casa de El Liberal en la calle del Marqués de Cubas, números 5 y $7^{46}$. La actitud de la SEU contra el golpe de Estado y la dictadura del general Primo de Rivera, así como su desafección a la monarquía, le harán recuperar a Heraldo, de la mano de figuras tan reconocidas como Manuel Fontdevila (1887-1957) -como director desde 1927- y con Manuel Chaves Nogales (1897-1944) como redactor-jefe; así como a El Liberal de Francisco Villanueva (1875-1946) -desde 1924-, la influencia que habían perdido en años anteriores, recobrando poco a poco su prestigio anterior, siendo ambos medios periodísticos determinantes en la creación del ambiente político e intelectual que propiciaría el giro republicano de 1931. No puede extrañar, por tanto que el primorriverista La Nación les acusara - el 12 de marzo de 1931- de ser "los periódicos del barullo", asegurando al mismo tiempo que "esta es la Prensa que pide libertad y que habla de leyes tiránicas", pero "si en España hubiera leyes que amparasen a los ciudadanos, como en Inglaterra, y se cumplieran, ¿podría el Heraldo salir a la calle un solo día?".

La prensa, mientras tanto, se industrializaba a pasos agigantados en la tercera década del siglo XX. Uno de los grandes protagonistas de este proceso será el empresario madrileño Luis Montiel y Balanzat (1884-1976). Desde 1 de agosto de 1919 flamante propietario de los monumentales Talleres Tipográficos Sucesores de Rivadeneyra ${ }^{47}$. Desde esta industria editorial se lanzaría a poner en marcha, tras una minuciosa prospectiva, dos exitosas publicaciones, la revista de información general Estampa y el diario gráfico Ahora. En concreto, Estampa: revista gráfica y literaria de la actualidad española y mundial (1928-1938) empezaría su brillante andadura el 3 de enero de 1928. Ejemplo de modernidad, por su adaptación a las modernas técnicas de impresión, en el caso de Estampa se conseguirá también un notable abaratamiento del precio de venta del ejemplar frente a todos sus competidores.

Este acierto llevaría a su propietario a lanzar, en la emblemática fecha de 16 de diciembre de 1930 coincidiendo con la sublevación de Jaca- el ambicioso periódico Ahora: diario gráfico, uno de los medios periodísticos más leídos durante los años republicanos, tanto por su excelente calidad técnica, información y reportajes ágiles como por su línea editorial equilibrada y contar con la subdirección del aclamado periodista Manuel Chaves Nogales y algunas de las más notorias firmas del momento, entre otros, Unamuno, Baroja, Maeztu, Valle Inclán, Madariaga... ${ }^{48}$

El empuje empresarial de Montiel forzaría a su gran rival en el segmento de las revistas ilustradas, la sociedad Prensa Gráfica de Urgoiti, Mariano Zavala y Francisco Verdugo Landi -editora de Nuevo Mundo, Mundo Gráfico y La Esfera - a lanzar al mercado, desde la que era su nueva sede, desde 1915, en la calle de Hermosilla, número 57, Distrito de Salamanca, el 17 de noviembre de 1929 la revista Crónica: revista de la semana (1929-1938), en un renovado intento por afianzarse, frente a la competencia, en un sector tan dinámico y en alza como el moderno fotoperiodismo. Para ello, haría gala de un carácter más politizado -y con ciertos tintes eróticos- que la más conservadora en sus contenidos Estampa y ocupando el espacio de la izquierda republicana. Así pues, una vez más, una revista ilustrada nacía como respuesta a una exitosa publicación rival. Crónica llegaría también a alcanzar un gran éxito durante el periodo de la Segunda República.

De este modo, se puede afirmar que la ingente labor editorial de empresarios como Urgoiti, Montiel y Busquets sería fundamental en el profundo cambio histórico que se avecinaba en la cuarta década del siglo XX. La República de los intelectuales, de la que habló Azorín -en el periódico Crisol de 4 de junio de 1931- no hubiera sido posible, indudablemente, sin el empeño profundamente renovador y reformista de los promotores

\footnotetext{
"La Sociedad Editorial de España”, La Época, 29 de noviembre de 1922.

Gil Toll, Heraldo de Madrid, tinta catalana para la II República española, Sevilla, Renacimiento, 2013, págs. 74-76.

Carlos Sampelayo, "Los delitos legales de la Dictadura: el caso de la prensa republicana", Tiempo de Historia, número 49, diciembre de 1978, págs. 26-39.

47 Su trayectoria biográfica más completa en Juan Carlos Sánchez Illán, "Luis Montiel y Balanzat”, Diccionario Biográfico Español de la Real Academia de la Historia: http://dbe.rah.es/biografias/luis-montiel-balanzat

48 Veáse Jesús de Juana López, La posición centrista durante la Segunda República: (el periódico 'Ahora', 1930-1936), Santiago de Compostela, Servicio de Publicaciones de la Universidad, 1988.
} 
de todas estas grandes empresas periodísticas. Por todo ello, no puede extrañar que el intelectual alicantino, como veterano colaborador de la prensa, se permitiera afirmar -dirigiéndose a las nuevas élites republicanasque "vosotros, los que ocupáis el poder, habéis sido los parteros de la República; pero permitidnos que os digamos que quienes la han engendrado hemos sido nosotros. Nosotros, unos humildes y otros ilustres, los que a lo largo de treinta años hemos hecho poco a poco, con trabajo, con perseverancia, que el cambio de la sensibilidad nacional se efectúe. Y eso os debe obligar a vosotros, los gobernantes, primero, a la modestia, y luego, a la serenidad. La serenidad que es preciso que tenga quien gobierna para todos y quien tiene la trascendental misión da hacer que la República se levanta por encima de las pasiones y de los resentimientos personales". 